\title{
Correction to: A Framework for Understanding the Empowerment Effects of Telecentres on Rural Communities in Developing Countries
}

\author{
Sellina Khumbo Kapondera (D), Roberta Bernardi (D), \\ and Niki Panteli 1
}

Correction to:

Chapter "A Framework for Understanding the Empowerment Effects of Telecentres on Rural Communities in Developing Countries" in: P. Nielsen and H. C. Kimaro (Eds.): Information and Communication Technologies for Development, IFIP AICT 551, https://doi.org/10.1007/978-3-030-18400-1_9

In the originally published version of this chapter, the name of the second author Roberta Bernardi was incorrect. The name of the author has been corrected. 